\title{
Vascular Surgery Pain Outcomes Improved by Implementing Hospitalist Comanagement Service
}

Chien Yi M Png, Peter L Faries, Lucia Y Qian, Irene T Lee, Rajiv Chander, David E Finlay, Michael L Marin and Rami O Tadros* Icahn School of Medicine at Mount Sinai, New York, NY 10029, USA

\section{Abstract}

Introduction and Objective: This preliminary study aims to investigate the impact of introducing a hospitalist comanagement service on inpatient vascular surgery pain outcomes.

Methods: A total of 2110 consecutive patients were studied: 717 patients who were managed before the comanagement system was implemented (May 2011 to December 2012) and 1393 who were comanaged (January 2013 to December 2014). The visual analog pain (VAP) scores (ranging from no pain to severe pain) of each patient were analyzed. In addition, two questions from the Hospital Consumer Assessment of Healthcare Providers and Systems (HCAHPS) survey were additionally analyzed.
\end{abstract}

Results: The comanaged cohort experienced significantly higher rates of patients reporting no pain (Comanaged: 82.97\% Not comanaged: $71.97 \%, p=<0.001$ ) and significantly lower rates of mild pain (Comanaged: $7.39 \%$ Not comanaged: $12.55 \%, p=<0.001$ ) and moderate pain (Comanaged: $7.68 \%$ Not comanaged: $13.11 \%, p=<0.001$ ). The rates of severe pain were similar between groups (Comanaged: $1.93 \%$ Not comanaged: $2.37 \%, p=0.51$ ). HCAHPS results showed increased rates of patients reporting that their pain was always well managed, as well as increased rates of patients reporting that the hospital staff always tried their best to manage their pain.

Conclusion: The implementation of a vascular co-management service resulted in significantly improved pain scores and improved HCAHPS scores.

Keywords: Co-management; Vascular surgery; Hospitalist comanagement; Inpatient; Pain score

\section{Introduction}

Pain management is one of the most common and serious problems in patients post-surgery [1,2]. Poor post-operative pain control has been linked to increased length of stay, incidence of pneumonia and other complications [3]. In addition, because post-operative pain is one of the most common concerns in patients [4], it is one of the most reliable predictors of patient satisfaction [5]. However, even with the numerous advancements in pain management, not all patients receive relief from post-operative pain [6]

Systems that facilitate co-management between surgical and medical physicians have been implemented across the country relatively recently. Current literature on such systems is limited to cardiothoracic, general surgical, neurosurgical and orthopedic patient populations, with varying results [7]. For instance, a randomized trial involving comanaged orthopedic patients showed a decrease in complication rates [8], while a similar system between neurosurgeons and hospitalists at a teaching hospital resulted in increased perceived quality of care and decreased costs (by $\$ 1500$ per visit) [9]. In another study focusing on a surgical co-management model implemented in pediatric residency program, one of the primary outcomes reported was gains in knowledge and skills by residents in pain management [10].

Because, traditionally, the vascular patient population has significantly increased medical comorbidities, treatment and care is often complex. As such, we expect these patients to benefit uniquely from a vascular co-management program by having both experienced hospitalists and vascular surgeons working as a team to provide optimal patient care.

\section{Methods}

\section{Patient population and data collection}

This study was performed at the Mount Sinai Medical Center and the Icahn School of Medicine at Mount Sinai, an urban tertiary care hospital and medical school. A retrospective review was performed on 2110 consecutive patients who were seen at Mount Sinai [11]. All patients met inclusion criteria. Because the vascular surgeonhospitalist co-management program was implemented in January 2013, this resulted in a cohort of 717 patients who were seen without co-management between May 2011 and December 2012, and a cohort of 1393 patients who were co-managed between January 2013 and December 2014. The data were collected from the Office for Excellence in Patient Care Reporting System of the medical school. Institutional Review Board approval was waived because patients were not directly studied, and patient informed consent was not needed because the data collected were retrospective and deidentified [12].

\section{Statistical analysis}

All data was analyzed using Statistical Analysis System (SAS Institute). Pain scores breakdowns were analyzed using chi-squared tests. Hospital Consumer Assessment of Healthcare Providers and Systems (HCAHPS) survey results were also analyzed using chisquared tests.

${ }^{*}$ Corresponding author: Rami O. Tadros, MD, FACS, RPVI, Cahn School of Medicine at Mount Sinai, New York, NY 10029, USA, Tel: 212-241-5393; E-mail: rami.tadros@mountsinai.org

Received December 15, 2015; Accepted January 05, 2016; Published January 09, 2016

Citation: Png CYM, Faries PL, Qian LY, Lee IT, Chander R, et al. (2016) Vascular Surgery Pain Outcomes Improved by Implementing Hospitalist Comanagement Service. Pain Manage Med 1: 109

Copyright: $\odot 2016$ Png CYM, et al. This is an open-access article distributed under the terms of the Creative Commons Attribution License, which permits unrestricted use, distribution, and reproduction in any medium, provided the original author and source are credited. 


\section{Results}

\section{Pain scores}

There were 717 patients in the pre-co-management cohort. Of these patients, 516 reported no pain, 90 reported mild pain, 94 reported moderate pain and 17 reported severe pain while being managed. In comparison, of the 1393 patients in the co-managed cohort, 1156 reported no pain, 103 reported mild pain, 94 reported moderate pain and 17 reported severe pain while being managed. The co-managed cohort had a significantly higher percentage of patients reporting no pain (Co-managed: $82.97 \%$ Not co-managed: $71.97 \%, \mathrm{p}=<0.001$ ). Significantly lower rates of mild pain (Co-managed: $7.39 \%$ Not comanaged: $12.55 \%, \mathrm{p}=<0.001$ ) and moderate pain (Co-managed: $7.68 \%$ Not co-managed: $13.11 \%, \mathrm{p}=<0.001)$ were also observed. The rates of severe pain were similar. (Co-managed: $1.93 \%$ Not co-managed: $2.37 \%$, $\mathrm{p}=0.51)$ (Figure 1).

\section{HCAHPS survey results}

There were 46 survey responses in the pre-co-management cohort, and 171 survey responses in the co-managed cohort. The co-managed cohort had a higher percentage of patients responding with "Always" to the question "How often did the hospital staff do everything they could to help you with your pain?" (Co-managed: 59.06\% Not comanaged: $52.17 \%, \mathrm{p}=0.40$ ) (Figure 2). A similar trend was observed for the question "During this hospital stay, how often your pain was well controlled?" (Co-managed: $73.68 \%$ Not co-managed: $69.57 \%, p=0.58$ ) (Figure 2).

\section{Discussion}

There is a relative paucity of current literature on the effects of vascular co-management services patient outcomes [12]. Further, there is much less information available on pain management in this select patient cohort. Notably, pain control and management was ranked first (followed by fluid and electrolytes, respiratory care, and nutrition management) in a survey asking pediatric residents which areas they felt the co-management of patients helped them learn most [10].

Our pain score data suggests that co-managed patients benefit in terms of reduced rates of overall pain, seen by significantly increased rates of "No pain" while significantly decreased rates of "Mild pain" and "Moderate pain". One likely cause of these improvements is the combination of experience and knowledge of hospitalists and vascular surgeons resulting in better overall treatment. Another point to consider

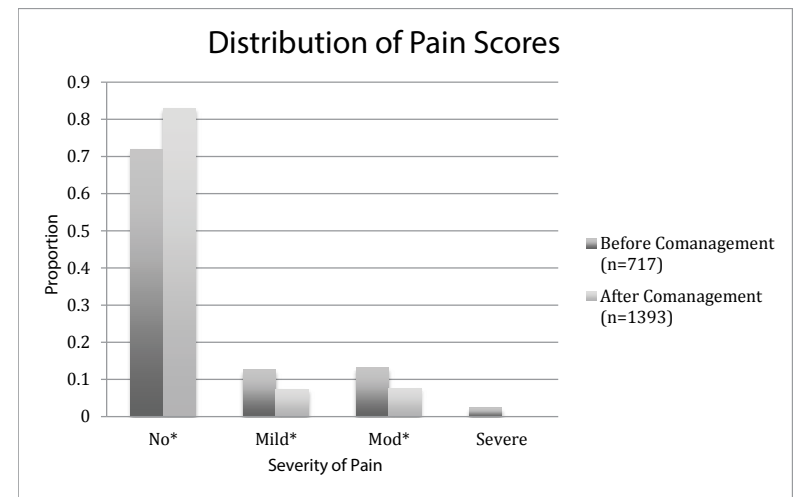

Figure 1: Comparison of pain score distribution between the cohort that was comanaged and the cohort that was not comanaged. *Significant in chi-squared analysis to $p<0.001$.

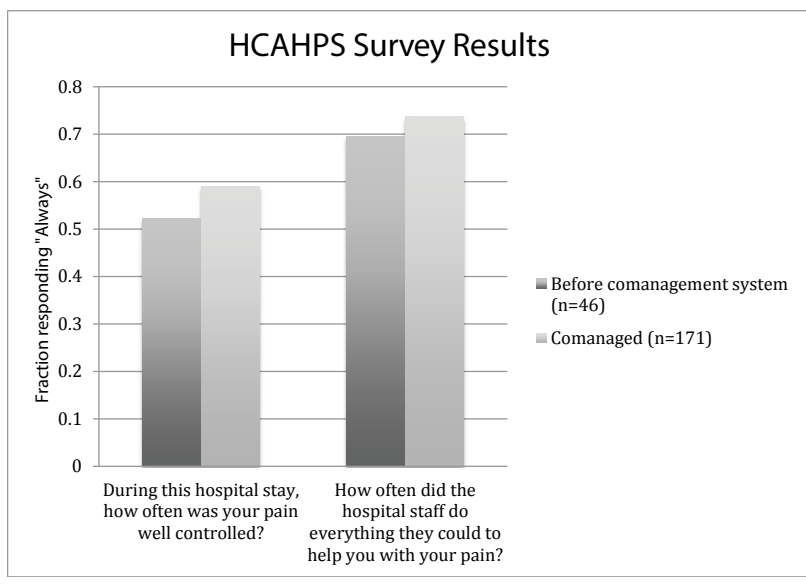

Figure 2: Comparison of HCAHPS questions between the cohort that was comanaged and the cohort that was not comanaged.

is the timing of pain management, as unrelieved pain immediately following surgery is a risk factor for the development of chronic pain [13]. We anticipate that with co-management, patients in distress would have the opportunity to be seen quicker as either the hospitalist or the surgeon could tend to them. Rates of "Severe pain" decreased as well, but did not reach significant levels. This relatively low decrease in rates of "Severe pain" could be explained by the small cohort compared and may be part of a subset of patients with pain who would not perceive benefit from any current pain management therapies [6].

Our HCAHPS survey data showed increases in rates of patients reporting that their pain was always well managed, as well as rates of patients reporting that their hospital staff always did everything they did to help with pain management. These increases did not achieve significance, likely due to the relatively small number of patients who filled out the survey. Historically, it has been shown that patient satisfaction correlates more strongly with the perception that caregivers did everything they could to manage pain than with pain actually being well managed [14]. Indeed, the rates of patients believing that their pain was always well managed increased by around $4 \%$, while the rates of patients believing that their hospital staff did everything to help with pain management increased almost by $7 \%$.

Finally, survey responses from our residents and doctors have been overwhelmingly positive [12]. This is in line with the trend with feedback from nurses and doctors regarding co-management systems being generally positive at other institutions [15].

\section{Limitations}

A major limitation of this study is the lack of individualized patient data, which prevented more sophisticated multivariate analysis that would control for the characteristics of the patient.

\section{Conclusion}

The implementation of a vascular co-management service has had a positive impact on pain outcomes. Analysis over a four-year period has revealed significant improvements in pain scores as well as patient perceptions of pain management. We would recommend introducing similar co-management systems at other institutions, and will continue to track progress at our hospital system.

\section{Acknowledgements}

We would like to thank John Santiago for assisting with data collection. 
Citation: Png CYM, Faries PL, Qian LY, Lee IT, Chander R, et al. (2016) Vascular Surgery Pain Outcomes Improved by Implementing Hospitalist Comanagement Service. Pain Manage Med 1: 109.

\section{References}

1. Jenkins JT, O'Dwyer PJ (2008) Inguinal hernias. BMJ 336: 269-272.

2. Macrae WA (2008) Chronic post-surgical pain: 10 years on. $\mathrm{Br} \mathrm{J}$ Anaesth 101 $77-86$

3. Carr DB, Goudas LC (1999) Acute pain. Lancet 353: 2051-2058.

4. Vadivelu N, Mitra S, Narayan D (2010) Recent advances in postoperative pain management. Yale J Biol Med 83: 11-25.

5. Glowacki D (2015) Effective pain management and improvements in patients' outcomes and satisfaction. Crit Care Nurse 35: 33-41.

6. Shoar S, Esmaeili S, Safari S (2012) Pain management after surgery: a brief review. Anesth Pain Med 1: 184-186.

7. Huang J (2014) Co-management of surgical patients. J Med Pract Manage 29: 348-350.

8. Huddleston JM, Long KH, Naessens JM, Vanness D, Larson D, et al. (2004) Medical and surgical comanagement after elective hip and knee arthroplasty: a randomized, controlled trial. Ann Intern Med 141: 28-38.

9. Auerbach AD, Wachter RM, Cheng HQ, Maselli J, McDermott M, et al. (2010)
Comanagement of surgical patients between neurosurgeons and hospitalists. Arch Intern Med 170: 2004-2010.

10. Carr AM, Irigoyen M, Wimmer RS, Arbeter AM (2013) A pediatric residency experience with surgical co-management. Hosp Pediatr 3: 144-148.

11. Briones AGE, Chang D, Barna E, Asuen I, Dunn A (2014) Improving patient outcomes through implementation of a vascular surgery co-management service. Journal of Hospital Medicine 9: 2.

12. Tadros RO, Faries PL, Malik R, Vouyouka AG, Ting W, et al. (2015) The effect of a hospitalist comanagement service on vascular surgery inpatients. $J$ Vasc Surg 61: 1550-1555

13. Kehlet $\mathrm{H}$, Jensen TS, Woolf CJ (2006) Persistent postsurgical pain: risk factors and prevention. Lancet 367: 1618-1625

14. Hanna MN, Gonzalez-Fernandez M, Barrett AD, Williams KA, Pronovost $P$ (2012) Does patient perception of pain control affect patient satisfaction across surgical units in a tertiary teaching hospital? Am J Med Qual 27: 411-416.

15. Shelton A, Jones D, Story DA, Heland M, Bellomo R, et al. (2013) Survey of attitudes of nurses and junior doctors to co-management of high risk surgical patients. Contemp Nurse 44: 189-195. 